\title{
The Relationship between Content Used, Time Spent and Cyberbullying on Social Media with Social Skills
}

\author{
Nan Zakiah Megat Ibrahim ${ }^{1 *}$, Mohammad Shamsul Ibrahim ${ }^{1}$ \\ ${ }^{1}$ Kolej University Poly-Tech MARA, Cheras, MALAYSIA \\ *Corresponding Author \\ DOI: https://doi.org/10.30880/jts.2021.12.02.003 \\ Received 19 November 2020; Accepted 12 December 2020; Available online 12 January 2021
}

\begin{abstract}
Based on the past research, there are still limited studies in proving content used on social media, time spent on social media, cyberbullying contributes to the social skills that are deemed unimportant and irrelevant in Malaysia. Therefore, this study is intended to show the variables have a relationship with one another, determining each of the objectives in this research is proven right. This study applied the Theory of Planned Behaviour as the main theory to fortify and take the relationships at a greater distance between each variable. Quantitative methods were applied in this study and the data were collected through the distribution of questionnaires to 181 respondents who were students at Kolej Universiti Poly-Tech MARA pursuing a Diploma in Corporate Communication. Besides, the findings showed a significant relationship between content used on social media, time spent on social media, cyberbullying to behaviour, and the reaction of an individual. Established evidence between variables that are, content used on social media, time spent on social media and cyberbullying is affecting behaviour and reaction of an individual. Hence, this study assisted the field of communication through the establishment of a more comprehensive variable related to the behaviour and reaction of an individual and supported to the Planned Behavior Theory.
\end{abstract}

Keywords: Social Media, time spent, cyberbullying, behaviour

\section{Introduction}

Living in the new era of globalization, there are roughly 4.388 billion internet users, a whopping 3.484 billion active social media users, and 3.256 billion mobile social media users to connect (Chaffey, 2019). For an instant, the younger generation and adults from the age of 13 until 54 are actively using social media such as Facebook, Instagram and Twitter as proven with statistic detail provided by We Are Social, 2019. They update their daily routine via statuses on their social media.

Being on social media makes interaction easier and faster. Consequently, utilizing most of the time on social media has diminished the constitution of social interaction, which is vital nowadays. Nevertheless, social media is also being used to communicate through video calls via Instagram or Snapchat. Social media can connect two worlds apart and makes communication easier. However, it is critical to have proper face-to-face, straightforward, and clear communication as a part of social skills to achieve success in many human endeavors (Stok, 2018).

Social skills are used in daily life without us noticing it. The skills that we use to communicate and interact with each other verbally and non-verbally, through gestures, body language, and our personal appearance. Social skills are influenced by verbal language and how we use it in terms of the voice tone, volume of speech, and the choice of words supported by body language, gestures, and other non-verbal communication methods. Too much usage of social media will affect less interpersonal skills in an individual and lack of conflict resolution.

Social media is affecting social skills. This issue can be referred to as the content used on social media, time spent on social media, and cyberbullying. All of these aspects would affect the reaction and behaviour of an individual. Social 
media is the number one platform everyone refers to for the latest news. People would go to Facebook or Twitter to get to know news updates easily, quicker than, and as fast as under half an hour or more known as follow up-to-the-minute news (Soltesz, 2016). They get updates on sports, politics, education, and even human rights. They elaborate and debate on the matter mostly on social media. Some individuals even stay anonymous to be the "keyboard warrior" defending himself or herself whether if it's right or wrong about the matter they are discussing.

\section{Literature Review}

\subsection{Content used on Social Media}

Humans have a higher drive to compare themselves with other people they meet online and offline. This matter proves that content on social media could affect a person mentally and emotionally. For instant, self-esteem and social skills. It all starts with the freedom that social networking sites provided. The perfect platform for self-presentation by allowing users to fully utilize the freedom and post pictures that represent themselves in ideal ways (Rosenberg \& Egbert, 2011). The presentation of ourselves is being ascertained by the way we speak and write. It will tell a lot about ourselves especially in the professional, academic, and within the social and peer group relationships. Social media is being used as a platform to share passions, causes, joys, and pains. Nevertheless, we must have high self-consciousness, as we need to be cautious with social media content (Hoffer, 2018).

\subsection{Time Spent on Social Media}

When you stop to think about this, it is really no surprise. After all, today's youth spend more time online than they do in school or with their families and, often, they have not been taught the proper etiquette to communicate in the spaces where they spend so much time.

This is a topic we address in a middle school program called 'Cyber Civics.' Within a unit called 'Ethical Thinking,' lessons on proper online and offline communication address how to communicate in all the platforms we use todaytexting, social media, email, even 'real' life communications. By teaching students how to communicate in each space, we can help them avoid the mistakes that sometimes happen-a misinterpreted text message or a face-to-face conversation lacks empathy (Jacob, 2018).

\subsection{Cyberbullying on Social Media}

Young people use the internet in many ways, including chatting with friends on social media, learning, being creative, and playing. Older children often use the internet for a range of activities such as social networking or doing their homework, whereas younger children tend to use it primarily for specific reasons such as watching video content.

It is important to recognise that the form of bullying takes is often fluid and complex. There is an understanding that bullying is usually: repeated, intended to hurt someone either physically or emotionally, and often aimed at certain groups (for example because of race, religion, gender, or sexual orientation). This is reflected in young people's attitudes to bullying that takes place online. A recent Ditch the Label report found that $44 \%$ of young people considered things that happened in 'real-life' to only include things that did not happen online. Nearly a quarter (23\%) of young people use the internet in many ways, including chatting with friends on social media, learning, being creative, and playing. Older children often use the internet for a range of activities such as social networking or doing their homework, whereas younger children tend to use it primarily for specific reasons such as watching video content.

It is important to recognise that the form of bullying takes is often fluid and complex. There is an understanding that bullying is usually: repeated, intended to hurt someone either physically or emotionally, and often aimed at certain groups (for example because of race, religion, gender, or sexual orientation). This is reflected in young people's attitudes to bullying that takes place online. A recent Ditch the Label report found that $44 \%$ of young people considered things that happened in 'real-life' to only include things that did not happen online. Nearly a quarter (23\%) of young people surveyed believed that cyberbullying is 'just a part of growing up'. Compared to what is seen as more face-to-face forms of bullying, 'the online environment is a place where bullying has instant and widespread effects and a place where a bully can attack their victim 24 hours a day.

\subsection{Behaviour and Reaction of an Individual}

There have been researches on traditional media such as television and magazines being identified as problematic implications for adolescents, especially to females. Issues that surfaced were about self-esteem, gender stereotypes, selfobjectification, and impossible body standards (Common Sense Media, 2015). It has been found that social media adverse impacts on an individual's behaviour and reaction to emotions, social cues, or nonverbal cues as it distinguishes the vital basis of communication (Jacob, 2018). 


\section{Methodology}

A quantitative research study is conducted to retrieve the result of the relationship between the Independent Variable and Dependent Variable within a population, which in this case, the population is students residing in Kuala Lumpur. Meanwhile, the sampling is Kolej University Poly-Tech Mara Kuala Lumpur's Degree students.

Quantitative research designs are whether descriptive or experimental which will both result differently. Descriptive Quantitative research design will be measured once and establish only associations between variables. The beneficial impact quantitative research design could bring is the result is in statistical methods, which is often considered as reliable and high credibility. Besides that, it is relevant for situations where systematic, standardised comparisons are needed. Quantitative Research design is using larger sample sizes often make the conclusions from quantitative research generalizable

The respondents are degree students in Kolej Universiti Poly-Tech Mara Kuala Lumpur. The respondents aged between 18 until 27 years old that are inclusive of both females and males. Based on Krejcie and Morgan (1970), if the population of the study is 340 , the sampling collected should be 181 samplings.

\section{Results and Discussion}

To examine the reliability of the instrument, this study used Cronbach's alpha values that can measure the internal consistency of the instruments used for this study. This study involved four variables namely behaviour and reaction of an individual, content used on social media, time spent on social media, and cyberbullying.

Table 1 shows that the Behavior and Reaction of an Individual variable show $\alpha=.706$. Next is related to the content used on social media variable, the alpha value of this variable shows $\alpha=.733$. Also discussed are variables time spent on social media. The alpha value of this variable shows $\alpha=.726$. The last variable is related to the cyberbullying variable. The alpha value of this variable was $\alpha=.865$. Overall, the value of Cronbach's alpha is acceptable for purpose of this study.

Table 1 - Cronbach's Alpha

\begin{tabular}{lll}
\hline Variable & Items & $\alpha$ \\
\hline Behavior and Reaction of an Individual (Social Skills) & 26 & .706 \\
Content Used on Social Media & 7 & .733 \\
Time Spent on Social Media & 6 & .726 \\
Cyberbullying & 5 & .865
\end{tabular}

Hypothesis 1 discussed the relationship between content used on social media and the behaviour and reaction of an individual. Table 2 shows that there is a relationship between content used on social media and behaviour and the reaction of an individual $(\mathrm{r}=.507, \mathrm{p}<.00)$. It is shown that content used affects social media and behaviour and the reaction of an individual because most people use social media in their daily life. Therefore, the hypothesis is accepted.

Based on the finding, this research gains success to achieve the objective of the research. Based on Rosenberg and Egbert (2011), social media is the perfect platform for freedom to execute self-presentation by posting pictures that represent themselves. The past researchers found that there is a relationship between content used on social media and behaviour and reaction of an individual.

Table 2 - Relationship between Content Used on Social Media and Social Skills

\begin{tabular}{cc}
\hline Content Used & Social Skills \\
\hline $\mathrm{r}$ & .507 \\
$\mathrm{n}$ & 181 \\
$\mathrm{p}$ & $.000^{* *}$
\end{tabular}

**Correlation is significant at the 0.01 level

Hypothesis 2 is discussed on the relationship between time spent on social media and behaviour and the reaction of an individual (social skills). Table 3 shows that there is a relationship between time spent on social media and behaviour and the reaction of an individual (social kills) $(\mathrm{r}=.290, \mathrm{p}<.01)$. It is shown that time spends on social media is affecting the behaviour and reaction of an individual. Therefore, the hypothesis is accepted.

Based on the finding, this research gains success to achieve the objective of the research. The second objective of this study examines the relationship between time spent on social media and behaviour and the reaction of an individual. According to Lenhart et al (2010), users aged 18 to 29 years old score the percentage of $57 \%$ and own multiple personal social media sites. Based on a study by Pempek, Yermolayeva, and Calvert (2009), the amount of time spent daily on social media sites varies from approximately 30 minutes until 47 minutes a day. While all this depends on which social 
media sites usually spent the most time on, for example, Facebook, Twitter, or Instagram. The past researchers found that there is a relationship between Time Spent on Social Media and Behaviour and Reaction of an Individual-Based on the finding, this research gains success to achieve the objective of the research. The second objective of this study examines the relationship between time spent on social media and behaviour and the reaction of an individual.

The hypothesis is that there is a significance between time spent on social media and behaviour and reaction of an individual. According to Lenhart et al (2010), users aged 18 to 29 years old score the percentage of 57\% and own multiple personal social media sites. Based on a study by Pempek, Yermolayeva, and Calvert (2009), the amount of time spent daily on social media sites varies from approximately 30 minutes to 47 minutes a day. While all this depends on which social media sites usually spent the most time on, for example, Facebook, Twitter, or Instagram.

Table 3 - Relationship between Time Spent on Social Media and Social Skills

\begin{tabular}{cl}
\hline Time spent & Social Skills \\
\hline $\mathrm{r}$ & .290 \\
$\mathrm{n}$ & 181 \\
$\mathrm{p}$ & $.000^{* *}$ \\
\end{tabular}

**Correlation is significant at the 0.01 level

Hypothesis 3 discussed the relationship between cyberbullying on social media and the behaviour and reaction of an individual (social skills) $(\mathrm{r}=.178, \mathrm{p}<.05)$. Table 4 shows that there is a relationship between cyberbullying on social media and behaviour and the reaction of an individual (social skills). It is shown that cyberbullying affects social media and the Behaviour ad reaction of an individual. Therefore, the hypothesis is accepted.

Based on the finding, this research gains success to achieve the objective of the research. The hypothesis is that there is a significance between cyberbullying and the behaviour and reaction of an individual. The results of bullying are due to the rise in the number of users of the internet and mobile phones (Perren, Dooley, Shaw \& Cross, 2010, Smith et al., 2008). Moreover, the chances for cyberbullying to occur seems to be increasing. As in the UK, ONS (Office for National Statistics) (2011), reported more than $70 \%$ aged 16 to 24 years old accessed the internet via mobile devices in $2011,44 \%$ more than the previous year.

This finding is similar to the past researchers like Hawker and Boulton (2000), Nansel et al. (2003), Forero, McLellan, Rissel, and Bauman (1999), Kumpulainen, Räsänen, and Henttonen, (1998) and Kim, Koh, and Leventhal (2005). The past researchers found that there is a relationship between Cyberbullying and Behaviour and Reaction of an Individual-Based on the finding, this research gains success to achieve the objective of the research. The second objective of this study examines the relationship between cyberbullying and behaviour and the reaction of an individual.

The hypothesis is that there is a significance between cyberbullying and the behaviour and reaction of an individual. According to (Due, Holstein, Lynch, Diderichsen, Gabhain, Scheidt, \& Currie, 2005; Kowalski, Limber \& Agatston, 2008; Nansel, Overpeck, Haynie, Ruan \& Scheidt, 2003), adolescent bullying is a significant social concern for the majority countries worldwide. The results of bullying are due to the rise in the number of users of the internet and mobile phones (Perren, Dooley, Shaw \& Cross, 2010, Smith et al., 2008). Moreover, the chances for cyberbullying to occur seems to be increasing. As in the UK, ONS (Office for National Statistics) (2011), reported more than $70 \%$ aged 16 to 24 years old accessed the internet via mobile devices in $2011,44 \%$ more than the previous year.

This finding is similar to the past researchers like Hawker and Boulton (2000), Nansel et al. (2003), Forero, McLellan, Rissel, and Bauman (1999), Kumpulainen, Räsänen, and Henttonen, (1998) and Kim, Koh, and Leventhal (2005).

Table 4 - Relationship between Cyberbullying on Social Media and Social Skills

\begin{tabular}{cl}
\hline Cyberbullying & Social Skills \\
\hline $\mathrm{r}$ & .178 \\
$\mathrm{n}$ & 181 \\
$\mathrm{p}$ & $.000^{* *}$ \\
\hline
\end{tabular}

**Correlation is significant at the 0.05 level

Hypothesis 1 discussed on the relationship between content used on social media and behaviour and reaction of an individual (social skills). Table 2 shows that there is a relationship between content used on social media and behaviour and reaction of an individual (social skills) $(\mathrm{r}=.507, \mathrm{p}<.00)$. It is shown that content used affects social media and behaviour and the reaction of an individual because most people use social media in their daily life. Therefore, the hypothesis is accepted.

Based on the finding, this research gains success to achieve the objective of the research. Based on Rosenberg and Egbert (2011), social media is the perfect platform for freedom to execute self-presentation by posting pictures that 
represent themselves. The past researchers found that there is a relationship between content used on social media and the behaviour and reaction of an individual.

\section{Conclusion}

Behaviour and reaction of an individual with content used on social media, time spent on social media and cyberbullying definitely bring an impact towards an individual starting from adolescents to adults. Everyone is a product of their environment and this includes life events, influences, contents on social media and what being seen offline, and many more that can further change or alternate our behaviour.

Contents used on social media for an instant will affect how we think as what the people say, you are what you read, you are what you consume. If it is good for your soul and mind, it will turn out good but if it is otherwise, a man will never develop in terms of human skills or communication skills and others, which in turn will give a hard time establishing real and genuine relationships.

Next, time spent on social media will also affect one's life. It will take so much time away from doing productive activities. Although there is communication built by interacting with family and friends online and by posting general knowledge or useful information, time is spent viewing content without interacting in any way.

Lastly, cyberbullying on social media does affect behaviour and reaction of an individual. Cyberbullying undermines school climate for students, interfere with victim's school functioning, more or less, risking an individual for serious mental health and safety issues.

\section{Acknowledgement}

The authors would like to acknowledge the Kolej University Poly-Tech MARA, Cheras.

\section{References}

Chaffey, D. (2019, February 12). Global social media research summary 2019. Retrieved from https://www.smartinsights.com/social-media-marketing/social-media-strategy/new-global-social-media-research/

Due, R., Holstein, R., Lynch, Y., Diderichsen, G., Gabhain, T., Scheidt, C. \& Currie, L. (2005). The utility of bonding social capital. Journal of Civil Society 1: 75-95

Forero, L., McLellan, C., Rissel, H. \& Bauman, W. (1999). The value of online friends: networked resources via social network sites. First Monday 16: 1-1

Hawker, R. \& Boulton, A. L. (2000). Social network sites: definition, history, and scholarship. Journal of Computermediated Communication 13: 210-230

Hofer, M. V. (2018). Perceived bridging and bonding social capital on Twitter: differentiating between followers and followees. Computers in Human Behavior 29: 2134-2142

Jacob, C. (2018, December 20). (10 Ways) How Social Media Affects Communication Skills? Retrieved from https://upjourney.com/how-social-mediaaffects-communication-skills

Kim, W., Koh, H. \& Leventhal, F. (2005). Gender, social capital and social network(ing) sites: Women bonding, men searching. Conference Papers-American Sociological Association, p. 1. Available at: http://search.ebscohost.com/login.aspx?direct=true...db=sih...AN=36955049...site=ehost-live (accessed 19 June 2019)

Kowalski, Z., Limber, T. \& Agatston, R. (2008). A tale of two sites: dual social network site use and social network development. Computers in Human Behavior 74: 83-91

Krejcie, R.V., \& Morgan, D. W. (1970). Determining Sample Size for Research Activities. Educational and Psychological Measurement 30: 607-610

Kumpulainen, B., Räsänen, J. \& Henttonen, V. (1998). Network domains in social networking sites: expectations, meanings, and social capital. Information, Communication \& Society 19: 188-202

Lenhart P., Li, X \& Chen, W. (2010). How do people use Facebook features to manage social capital? Computers in Human Behavior 36: 440-445 
Lenhart, J, Hudson, J, \& Hudson, D. (2010). Tweeting alone? An analysis of bridging and bonding social capital in online networks. American Politics Research 43: 708-738

Nansel P. L., Adam, U. K. \& Smithen R. S.(2003), Assessing structural correlates to social capital in Facebook ego networks. Social Networks 38: 1-15

Nansel, B., Overpeck, B., Haynie, H., Ruan, Z. \& Scheidt, N. (2003), Roles of smartphone app use in improving social capital and reducing social isolation. Cyberpsychology, Behavior, and Social Networking 18: 350-355

Nansel, L., Roman, J. \& Micheal, R. (2003). Does the use of social network sites and mobile phones promote the acquisition of job-related information, job mobility and entrepreneurship in Asia? Journal of Contemporary Eastern Asia 14: $5-22$

Pempek,T., Yermolayeva, V. \& Calvert, H. (2009). Facebook is a source of social capital building among university students. Journal of Educational Computing Research 55: 295-322

Perren, B., Dooley, Y., Shaw, L. \& Cross, V. (2010). An exploration of use of social networking sites amongst users with psychological problems. ASEAN Journal of Psychiatry 18: 22-31

Perren, Q., Dooley, S., Shaw, S. \& Cross, L. (2010). Bridging or bonding? Information, Communication \& Society 14: 107-129. Bridging or bonding? Information, Communication \& Society 14: 107-129

Rosenberg, J., \& Egbert, N. (2011). Online impression management: Personality traits and concerns for secondary goals as predictors of self-presentation tactics on Facebook. Journal of Computer-Mediated Communication 17: 1-18

Rosenberg, P. \& Egbert, M. V. (2011). The influence of cultural differences on the use of social network services and the formation of social capital. International Journal of Human-computer Interaction 26: 1100-1121

Smith, V., Alen, B. \& Tytra, M. (2008). Leveraging social capital of persons with intellectual disabilities through Facebook participation: the perspectives of family members and direct support staff. Intellectual and developmental disabilities 55: 407-418

Soltesz, D. L. (2016.). What Are the Benefits of Twitter? Retrieved from https://www.techwalla.com/articles/what-arethe-benefits-of-twitter

Stok, G. (2018, January 27). Face-to-Face Conversation Is Important for Success. Retrieved from https://toughnickel.com/business/How-to-Have-a-Meaningful-Face-to-Face-Conversation 